\title{
Impact of Overhead Costs Apportionment on Selling Price Determination in Malaysian Automobile Manufacturing Industry
}

\author{
Kabiru Isa Dandago (Corresponding Author) \\ Visiting Professor of Accounting, School of Accountancy, College of Business \\ Universiti Utara Malaysia, 06010 UUM Sintok, Kedah Darrul Aman, Malaysia \\ Tel: 60-14-303-2297_E-mail: kidandago@gmail.com
}

\author{
Zulaikha Rabitah Zaidi \\ School of Accountancy, College of Business, Universiti Utara Malaysia \\ 06010 UUM Sintok, Kedah Darul Aman, Malaysia \\ E-mail: zulaikharabitahzaidi@yahoo.com
}

Received: March 15, 2014 Accepted: April 28, $2014 \quad$ Published: June 1, 2014

doi:10.5296/ajfa.v6i1.5291ＵRL: http://dx.doi.org/10.5296/ajfa.v6i1.5291

\begin{abstract}
This study aims to examine the impact of overhead cost apportionment on selling price determination in the Malaysian automobile manufacturing industry. Specifically, the study looks at the treatment of overhead costs apportionment from the perspective of the profit making effort of automobile manufacturing firms. The methodology used is interview with staff of one automobile manufacturing company in Malaysia taken as a case study: that is Naza Automotive Manufacturing Sdn. Bhd. The findings of this study show that overhead costs apportionment has significant impact on the determination of "true and fair" selling price of an automobile manufacturing firm, especially as service centres are considered in primary apportionment before their shares are re-apportioned to production centres, using an appropriate method. This study, therefore, recommends that automobile manufacturing firms in Malaysia should adopt the activity based costing method of overhead costs apportionment as it considers service centres of the company together with production centres in fair apportionment of overhead costs, taking into account the percentage of services enjoyed by the production centres from the service centres. This would allow room for fairly accurate
\end{abstract}




\section{Macrothink}

Asian Journal of Finance \& Accounting ISSN 1946-052X 2014, Vol. 6, No. 1

determination of total cost per unit of their products, which would ultimately lead to effective pricing decision.

Keywords: Overhead costs, Cost apportionment, Activity Based Costing, Selling Price, Automobile Manufacturing Industry 


\section{Introduction}

There are two major types of costs involved in manufacturing firms: direct costs and indirect costs. Direct costs are the costs which can be traceable physically and directly to a product or service; while the reverse applies for indirect costs. Although they cannot be traced directly to the product or service itself, however, it is extremely important to ensure that indirect costs are apportioned accurately, as the amount significantly impacts on the pricing decision of a manufacturing business. Manufacturing has been defined by Business Dictionary in the website (http://www.businessdictionary.com/definition/manufacturing.html) as "the process of converting raw materials, components, or parts into finished goods that meet a customer's expectations or specifications. Manufacturing commonly employs a man-machine setup with division of labor in a large scale production". Thus, producing automobiles is a manufacturing activity since all the parts are to be combined by machine and labor; passing through a number of stages before producing the finished goods in the form of completed vehicles.

Overhead costs are usually closely related to the factory or production activities out of which goods are produced. But service/performance centres also incur overhead cost which cannot be directly attributed to a particular product. General overhead costs incurred in the course of the activities of production and service centres in a manufacturing firm are to be summed up for fair apportionment to all the centres, as a first step, and then the service centres' shares re-apportioned to the production centres as a second step, using appropriate methods of primary and secondary apportionment of overhead costs. Examples of overhead costs are water and electricity bills, safety and environmental costs, and insurance for the machinery and other fixed assets used in production.

Guy (1997: 228) explains that, “choosing the best method of overhead cost apportionment is a topic which has been dealt with many times in management accounting discourse by advocates of different methods which can be used by accountants and controllers to gauge margins and profits". This supports the fact that the method used to apportion overhead costs plays a crucial role in influencing the pricing decision on a product and the overall performance of a firm, specifically a manufacturing firm that has to consider all costs incurred in determining the selling price per unit of its product.

Overhead costs apportionment is crucial for manufacturing companies from different perspective, especially for profit determination. The challenge of fairly apportioning overhead costs has become very important nowadays since overhead cost is a major player in determining the profitability level of manufacturing firms. This challenge includes adoption of the most suitable method to apportion overhead costs and how the apportionment of these costs will amount to optimum pricing decision and enhance the financial performance of the firm.

Traditionally, primary apportionment of overhead costs is done to all the cost centres (production and service/performance centres), using any of the numerous methods available. For fairness to be ensured, the shares of the service centres overhead costs are to be re-apportioned to the production centres or products based on the percentage services 
rendered to them, using any of the secondary apportionment methods like Direct method, Continuous allotment method, Step method, etc. As the indirect costs are fairly apportioned to production centres and ultimately to each unit produced, total cost per unit can now be determined since material and labour costs have already been traced. It is then that pricing decision could be scientifically made, taking into account the target profit to add to the total cost per unit and, of course, the acceptance of the selling price by the market.

Overhead costs apportionment, therefore, needs serious attention from manufacturing firms, especially those in export-oriented countries like Malaysia. Naza Automotive Manufacturing Sdn. Bhd. was selected for the study on treatment of overhead costs apportionment by automobile manufacturing firms in Malaysia in view of the fact that the company bears all the characteristic features of firms operating in that industry. It is hoped that studying the impact of overhead costs apportionment on selling pricing decision in Naza automotive manufacturing firm would throw light on how overhead costs are apportioned to all cost centres in the Malaysian automotive industry. This would give room for suggestion on the most appropriate treatment of overhead costs in that industry for better pricing decision.

This paper specifically examines the impact of overhead costs apportionment on selling price determination in the Malaysian automotive industry. The paper is divided into five sections, with the introduction above as its section 1. Section 2 reviews related literature. Section 3 is about statement of the methodology used in the study. Section 4 presents and discusses the results obtained, while section 5 concludes the paper.

\section{Literature Review}

\subsection{Conceptual/Theoretical framework}

Overhead cost is defined as indirect factory-related cost. It is a cost that is difficult to trace into the finished products. To exemplify overhead cost, the Management Accountancy website (http://www.managementaccountancy.com/2009/05/overhead-cost-allocation/) asks the question: is it possible to determine the costs of electricity used to produce one 'can' of soft drink? But each 'can' of soft drink deserves some share of the cost of electricity used in its production! Overhead costs, therefore, need to be treated with caution and seriousness so as to avoid wrong pricing decisions.

These overhead costs are also known as manufacturing overheads, factory overheads, factory burden and manufacturing support costs. To be precise, manufacturing overheads are the costs which the company incurs, other than the direct costs, for it to produce the finished products. The costs that can be included in this group of costs are handling and setting of manufacturing equipment, inspection of the products, maintenance of the machine, factory cleanliness, record keeping as well as monitoring and maintenance of the production line.

Mott (1991:6) states that, "The easy definition of indirect costs is to say that they are all costs which cannot be identified as direct costs! They are, therefore, costs which cannot be immediately identified with the end product going to customers, but which first must go through some intermediate channelling process”. This means that overhead cost is the cost 
which can only be traced to the finished products using suitable methods of primary and secondary apportionment.

According to Mott (1991:8), "when a cost can be charged in total to either a cost unit or a cost centre, without first being divided into smaller parts, we say it is allocated". Costs allocation also can be defined as cost assignment, cost apportionment and cost distribution. All of these terms explain the process of taking a given common cost and dividing it between various cost objects. Three steps are required to allocate costs: first, define the cost objects, second, accumulate the common costs to be assigned to the cost objects and third, choose a method for allocating common costs accumulated in step 2 to the cost objects defined in step 1 (Zimmerman, 2009:314).

Again, Zimmerman (2009:316) states that, “cost allocations are quite prevalent in manufacturing. Manufacturers cannot deduct all their manufacturing costs for financial reporting and tax purposes. Rather, they must trace their direct manufacturing costs and allocate their indirect manufacturing costs between units sold and units remaining in inventory". Hence, for calculating cost of goods sold, net income and cost of closing inventory, financial reporting standards require that indirect manufacturing costs are to be apportioned. Cost apportionment issue also arises whenever a firm has a cost-based reimbursable contract. In this case, the firm's revenues depend on reported costs, including allocated costs. This shows that selling price of a product depends to a large extent on the overhead costs apportioned to the product.

There are several methods of allocating overhead costs to cost centres. In this study, the examination of these methods is restricted to activity-based costing (ABC) method of total cost determination and traditional methods of overhead costs apportionment and total cost per unit determination.

\subsubsection{Traditional Overhead Cost Apportionment Method}

A well established method for allocating overhead costs is the traditional method. Horngren, Bhimani, Foster and Datar (1999) are of the view that the traditional approach of overhead cost apportionment often uses too few pools of indirect costs, so that cost allocations are overly broad averages. The resulting costs may lead managers to make erroneous decisions about pricing or product emphasis. This shows that traditional method does not emphasize on the need to "net" all indirect cost elements; it is concerned only with the few prominent indirect costs like depreciation, electricity charges, water bills, salary of administrative staff, etc.

Additionally, Jamaliah and Maliah (2008: 7) opined that "the traditional accounting approach for primary apportionment of overhead costs is about allocation based on labour hours or machine hours". The limitations of this method, according to them are that "it rarely reflects the true cause and effect of the relationship between indirect costs and individual products". Scholars like Bastl, Grubic, Templar, Harrison and Fan (2010) are of the view that the traditional accounting practice is mainly represented by standard costing, which often do not 
fulfil inter-organisational roles well enough to be considered relevant for decision making support.

Other explanations regarding traditional apportionment are offered by Chan and Lee (2003) who state that in using the traditional costing system, the allocation basis adopted in stage two (secondary apportionment) tend to be dominated by volume-related factors, such as number of direct labour hours, direct labour dollars and number of production units. However, these apportionment methods often do not reflect reality. Chan and Lee(2003) are, therefore, uncomfortable with the use of traditional method of overhead cost apportionment, especially using any the methods of secondary apportionment. To them the bases used are mostly subjective and, so, unreliable.

Since, the traditional method is just based on the number of direct labour hours, direct labour dollars and number of production units, there is the danger that it would lead to inaccurate and unreliable calculation of the total cost that is incurred to produce a unit of product. Thus, it is bound to lead a manufacturer to the determination of inaccurate and wrong selling price of the product. This would ultimately affect the overall performance of the business in the short- or long-run.

\subsubsection{Activity-Based Costing Method}

Gunasekaran, Marri and Yusuf (1999:287) explain that, "the ultimate goal of ABC as a cost allocation system is to trace the production costs generated by the production of goods or services, as accurately as desired, to the causing activities”. This means that activities are the bases of incurring direct and indirect cost, leading to the total cost of the activities necessary for the production of a unit of product or service. Synder and Davenport (1997), define $\mathrm{ABC}$ as an attempt to allocate overhead costs based on the activities that cause overhead costs to be incurred, rather than arbitrarily assigning overhead costs simply because the organisation incurs them. This method is simply about allocating overhead costs based on the activities leading to the production of goods or services.

Guy (1997) is of the view that ABC can be useful in avoiding allocation of charges into the cost of products that are not concerned with those charges. According to Jamaliah and Maliah (2008), ABC is a tool to help allocate overheads with a greater degree of accuracy. ABC has been defined as a method of measuring cost and performance of activities and products (Gunasekaran, Marri and Yusuf, 1999). From these explanations, it is clear that ABC is considered to be relatively accurate compared to other methods of overhead cost apportionment.

According to Horngren, Bhimani, Foster and Datar (1999), ABC focuses on activities as the fundamental cost objects. An activity is an event, task or unit or work with a specified purpose. ABC uses the cost of these activities as the basis for assigning costs (direct and indirect) to other cost objects, such as products, services or customers. This is another powerful viewpoint in support of ABC method which emphasizes on allocating overhead cost to the activities that incur them in the course of producing products or services. 
Marshall, McCartney, Van Rhyn, McManus and Viele (2010: 450) are of the view that ABC system has led to more accurate costing than older overhead application methods and has supported more effective management of the production, administrative and marketing functions of manufacturing firms. ABC method also makes it easier for performance/service departments to ascertain their running cost, as costing is purely based on activities undertaken.

Mott (1991) suggests that a more valid approach is to accumulate overhead costs not on a departmental basis but on an activity basis. This approach regards activities as incurring costs and products as consuming those activities. This way, overhead cost apportionment is clearly to be consumer (the relevant product) and, so, total cost per unit and selling price determination would not pose any technical problem.

Using ABC method of overhead cost apportionment, a company is bound to improve on its pricing decision making. This is supported by Jamaliah and Maliah (2008), who found that ABC adoption leads to better selling pricing decisions and eventually to an enhanced bottom line for a manufacturing or service organization. Other than that, ABC leads to the accurate calculation of the cost of goods and services as per the finding of Synder and Davenport (1997) that, the primary benefit of using ABC is that it ensures more accurate costing and that the related benefit of better costing is likely to be better managerial decisions.

Taking into account the supports ABC method enjoys from scholars and practitioners, whose works are reviewed, it is clear that activity-based costing is the more preferred method for overhead cost allocation/apportionment in the existing literature. This is due to the fairly accurate results that had been argued to be obtained using $\mathrm{ABC}$ in allocating/apportioning total cost to units produced. The expected accuracy in total cost per unit determination will lead to convincing selling price determination.

\subsection{Review of Empirical Studies}

There are many significant reasons for allocating manufacturing overhead costs to products. In price-setting process of manufactured products, the price should cover all the manufacturing costs, including direct and indirect costs. This indicates that overhead costs must be apportioned accurately to determine a reasonable and competitive price. Furthermore, the products which are yet to be sold, that is., closing inventory should be reported on the balance sheet a part of current assets. It is the requirement of accounting principles that inventory costs are presented in the financial statements; and that closing inventory, as a the balance sheet item must include not only the direct costs, but also overhead costs. Since overhead costs cannot be traceable directly in the products' physical appearance, there should be a special method to apportion it in order to fairly determine the cost of each product produced by a reporting entity.

Synder and Davenport (1997: 159) argue that: "there are two basic outcomes from allocating overhead cost to units produced: better economic decisions and higher level of managerial motivation”. Horngren, Bhimani, Foster and Datar (1999:135) mention four purposes for allocating indirect costs: to provide information for economic decisions, to motivate 
managers and employees, to justify costs or calculate reimbursement and to measure income and assets for reporting to external parties.

According to Armistead, Bowman and Newton (1995), the perception of the need to control overhead costs in the different service and manufacturing environments may depend more on the accuracy of accounting systems to measure cost of unit of product than on the nature of the service or manufacturing. The two are, however, linked to some extent. In manufacturing companies, the accounting systems are usually designed to measure cost of unit of product, including overhead cost allocation. While there is debate about accuracy of the traditional accounting process to make overhead cost apportionment as fairly as possible, the process is at the heart of control systems in manufacturing. In pure services, as characterised by professional services, the cost of unit of product is measured, to a lesser extent, by including the overhead allocation (Armistead, Bowman and Newton, 1995). The main control is, therefore, through utilisation of professional fee earning activity. Mixed and quasi-manufacturing service might be expected to lie somewhere between the two extremes of manufacturing and pure service.

All of these statements support the importance of fair apportionment of overhead costs. It is clear that overhead cost apportionment is really very important towards the determination of "true and fair" selling price of the products of manufacturing firms. A manufacturing firm should, therefore, chose the most appropriate methods of overhead cost apportionment that is suitable for its circumstances in order to arrive at a fairly accurate selling pricing decision, so as to enhance its sales as well as overall financial performance as a business.

In handling costing system, a manufacturing firm should appoint a dedicated person or team to be in charge of cost centre monitoring and to discharge the responsibility of cost management, especially to accurately overhead cost apportionment to cost centres and ultimately to cost units. Usually, in a manufacturing firm, the person involved in overhead costs apportionment and other cost management functions is designated cost accountant or management accountant. According to the Goergetown University website (http://provost.georgetown.edu/MCFO/nav/finmanresponsibilities/costcenter/), the cost manager (cost accountant) is an individual who has been delegated the responsibility for monitoring and reconciling the Cost Centre Status Reports (CCSRs), which suggests that the person in such a position has huge responsibilities to discharge including overhead costs apportionment of a manufacturing firm.

\section{Statement of Methodology}

The method of data collection used in conducting this study is interview. The interview was conducted with the chief internal auditor of Naza Automotive Manufacturing Sdn. Bhd. Naza, as an automotive manufacturing firm, was sampled for data collection because: (i) it is a fair sample representing all the automotive manufacturing companies in Malaysia; (ii) it is a firm producing motor vehicle as a finished product which involves high overhead costs; and (iii) it takes account of all overhead costs, ranging from the costs of security guards to utilities costs. 
For this study, qualitative accounting data were gathered from the interview with the internal auditor; a senior management staff of Naza Automotive Manufacturing Sdn. Bhd. An internal auditor, being the custodian of the internal control system of a firm, is expected to be very knowledgeable about the cost accounting system of the firm. He/she should also be very independent in commenting on the working of the system than the cost accountant who operates the system. This is the logic behind the conduct of the interview with the internal auditor.

From this interview, several important issues were discovered and are discussed in section 4.

\section{Results and Discussion}

An interview session was conducted with the Internal Auditor of Naza Automotive Manufacturing Sdn. Bhd. Six specific questions were asked during the interview session, particularly relating to the impact of overhead costs apportionment on the determination of selling price of the automotive manufacturing firm. From the responses in the interview, several major issues regarding the impact of overhead costs apportionment on selling price determination were identified for discussion.

\subsection{About the Background of Naza Automotive Manufacturing Sdn. Bhd.}

Naza Automotive Manufacturing Sdn. Bhd is a subsidiary of Naza Group of companies, based in Seoul, South Korea. It is located in Gurun, Kedah and was established in 1996 by the late Y. Bhg. Tan Sri Dato' Seri Utama SM Nasimuddin SM Amin. The philosophy of this company is building high value, high quality, safe and dynamic vehicles in accordance with its tagline; "The Power to Surprise". Its employees consist of management level staff and the labour-force drawn from among the local community (Malaysians).

The factory was built on an area of 140 acres, consisting of assembly plant, a two-storey office, a track for testing, lots for vendors and suppliers, accommodation for staff and recreation facilities. This factory is equipped with facilities such as body welding and painting, which is fully automated, assembly and pre-delivery inspection of the units, accessories, the test and simulation that includes equipment used to assess performance, endurance and quality of each unit of vehicle. This manufacturing firm produces various types of motor vehicles through its 85 representative branches in Malaysia (www.nazakia.com.my).This automotive manufacturing firm is fast becoming a competitor to local automotive manufacturers, like Proton and Perodua, as well as other automotive manufacturers in Malaysia. It is currently common to see Naza produced motor vehicles throughout the country.

\subsection{Method of Apportioning Overhead Costs to Products}

On the method used by the company to apportion overhead costs to products, below is the discussion on the internal auditor's response:

The first question is to look at the significance of choosing the method for apportioning overhead costs. This is because this method influences the costing system of a manufacturing firm. From the interview, it is found that Naza, as an automotive manufacturing firm, uses 
traditional method of overhead cost apportionment. The officer clearly stated that the direct overhead costs are allocated by model and according to standard hours or minutes. As for the indirect costs, the officer mentioned that they are apportioned to all the cost centres, including performance/service centres, as a first step. The service cost centres' shares of the indirect costs are thereafter re-apportioned to the production cost centres or allocated directly to the units of vehicles produced, based on the percentage services rendered to them by the service cost centres.

From this finding, it shows that Naza Automotive Manufacturing firm uses traditional method of apportioning overhead costs and that the traditional method is still relevant to the Malaysian automotive manufacturing companies, as testified by Naza Automotive Manufacturing Sdn. Bhd. It also shows that it is really important for the manufacturing firms to select an appropriate method to apportion overhead costs to all departments or centres, including performance centres, and that the apportionment of overhead costs is not to be done arbitrarily. The important thing to note here is that various methods of primary and secondary apportionment of overhead costs impact differently on the selling price to be determined for the products of the company.

\subsection{Price-setting}

The respondent was also asked on how the company arrives at the price per unit of its product. Below is the discussion on the response to the question:

Price-setting is very important since it determines the revenue or sales of a firm. It also leads to the profit performance of a manufacturing firm and helps determine whether the firm is doing well or not.

As for Naza automotive manufacturing company, the price set for its product comprises the total costs of material, labour, overheads and profit margin. All the costs elements are critically identified and calculated first in order to avoid losses. Then, in order to make sure that the profit of the company is increasing over time, Naza determines a reasonable rate for profit margin according to the quality that the company provides for its products. This is also to ensure the sustainability of the manufacturing firm. The box below illustrates how Naza Automotive Manufacturing Sdn. Bhd. derives its selling prices for each of its products.

$$
\text { Selling price }=\text { Material }+ \text { Labour }+ \text { Overhead }+ \text { Profit }
$$

The overhead cost component in the selling-price determination shows that overhead cost is really important and provides significant impact on the determination of selling-price.

\subsection{Roles and responsibility of costing department}

On the officer(s) of the company in charge of overhead costs apportionment, below is a discussion on the internal auditor's response:

The costing department is extremely important in a manufacturing firm since its major function is to deal with the core activities and business of the firm. The performance of this 
department will affect the performance of the firm because this is where the overhead costs apportionment process is handled and managed.

As for Naza Automotive Manufacturing Sdn. Bhd., the persons in charge of the overhead costs are the cost centre managers. These staffs play a crucial role in this automotive manufacturing firm since the overhead costs are controlled and operated by them. Naza accords high priority to the role of these personnel since the decisions they make in allocating costs will affect pricing decision and the overall performance of the automotive manufacturing firm.

\subsection{Maintaining quality of the product}

On how Naza reduces overhead costs and, at the same time, maintains the quality of its products, and how the two aspects relate to each other, we discuss the response of the internal auditor below:

Naza has its own system to cater for this. Overhead costs can be reduced by close monitoring on the actual amount incurred by every departmental head. Cost reduction programme is one of the initiatives to evaluate the items/areas that impact overhead costs. Action must be taken to control the impact of, and minimise the increase in, overhead costs. Examples of areas to assess are overtime, wastages and utilities, etc. Quality of the product is not directly related to overhead costs. Apart from trimming the size of labour force and its costs, other procedures such as increased supervision, quality control, and quality of raw materials contribute towards better quality of the products.

This shows that overhead costs apportionment is very useful in fairly determining total cost per unit since it reduces the risk of unfair allocation of indirect cost to cost units, thereby reducing the cost that might be unfairly allocated to a particular product. Costs reduction would lead to increased profits of individual products and this would enhance the overall performance of the company.

\subsection{Relationship between overhead costs apportionment and performance of the firm}

On whether or not effective overhead cost apportionment enhances the performance of Naza as a company, it is found that: effective overhead costs allocation definitely enhances the productivity and profitability performance of the company. The respondent mentioned that effective overhead cost apportionment leads to accurate price-setting, better decision-making and higher maintenance of product quality, all of which are key elements in enhancing the performance of a manufacturing firm, like Naza automotive manufacturing Sdn Bhd.

\section{Conclusion}

Naza Automotive Manufacturing Sdn. Bhd. is one of the productive automotive manufacturing firms in Malaysia and the firm shows that overhead costs apportionment is highly relevant to its selling price determination and enhancement of its overall performance. The method best suited to the company's needs must be selected since overhead costs involve a huge amount of money towards the production of finished vehicles in the firm. The profit of the firm will be negatively affected if the overhead costs are apportioned inaccurately. The 
total cost per unit of the vehicle produced by the firm is affected by the method chosen for overhead costs apportionment, like wise its price setting. It is the responsibility of the costing department of an automobile manufacturing company to ensure that an appropriate method of overhead costs apportionment is adopted to do accurate apportionment that would ensure accurate selling price determination, so that the overall performance of the company could be enhanced.

The recommendation that can be made to Naza Automotive Manufacturing Sdn. Bhd. and other Malaysian automobile firms is that they should learn to change their overhead costs apportionment system from the traditional method to the ABC method in order to have accurate calculation of the total costs per unit of their products. Furthermore, overhead apportionment using ABC method would enhance the overall performance of the firms, as the selling prices of their products would be determined more accurately and more reliably.

\section{References}

Armistead, C., Bowman, C., \& Newton, J. (1995). Managers' perceptions of the importance of supply, overhead and operating costs. International Journal of Operations \& Production Management, 15(3), 16-28. http://dx.doi.org/10.1108/01443579510080526

Bastl, M., Grubic, T., Templar, S., Harrison, A., \& Fan, I. S. (2010). Inter-organizational costing approaches: the inhibiting factors, The International Journal of Logistics Management, 21(1), 65-88. http://dx.doi.org/10.1108/09574091011042188

Chan, S. Y., \& Lee, D. S. Y. (2003). An empirical investigation of symptoms of obsolete costing systems and overhead cost structure. Managerial Auditing Journal, 18(2), 81-89. http://dx.doi.org/10.1108/02686900310455065

Gunasekaran, A., Marri, H.B., \& Yusuf, Y.Y. (1999). Application of activity-based costing: some case experiences. Managerial Auditing Journal, 14(6), 286-293. http://dx.doi.org/10.1108/02686909910280217

Guy, G. E. (1997). Using improper costing methods may lead to losses. The TQM Magazine, 9(3), 228-230.

Horngren, C. T., Bhimani, A., Foster, G., \& Datar, S. M. (1999). Management and cost accounting (10th ed.). New Jersey: Prentice Hall Europe

Jamaliah, A. M., \& Maliah, S. (2008). Implementation of activity based costing in Malaysia: A case study of two companies. Asian Review of Accounting, 16(1), 39-55

Marshall, D. H., McCartney, J., Rhyn, D. V., McManus, W., \& Viele, D. F. (2010). Accounting: what the numbers mean ( ${ }^{\text {nd }}$ ed). Australia: McGraw-Hill Australia Pty Ltd

Mott, G. (1991). Management accounting for decision makers $\left(2^{\text {nd }}\right.$ ed). London: Pitman Publishing.

Retrieved Oct 11, 2012, from World Wide Web: http://www.managementaccountancy.com/2009/05/overhead-cost-allocation/ 


\section{Macrothink institute}

Asian Journal of Finance \& Accounting ISSN 1946-052X 2014, Vol. 6, No. 1

http://blog.accountingcoach.com/manufacturing-overhead-allocated/

Retrieved Oct. 20, 2012, from the World Wide Web: www.nazakia.com.my

Retrieved Oct 31, 2012, from the World Wide Web: http://provost.georgetown.edu/MCFO/nav/finmanresponsibilities/costcenter/

Retrieved Nov 29, 2012, from the World Wide Web: http://www.businessdictionary.com/definition/manufacturing.html

Roslina, S. (2012, October 19). Interviewed by Zulaikha. Gurun: Naza Automotive Manufacturing Sdn Bhd (NAM)

Snyder, H., \& Davenport, E. (1997). What does it really cost? Allocating indirect costs. Asian Libraries, 6(3), 205-214. http://dx.doi.org/10.1108/10176749710368389

Zimmerman, J. L. (2009). Accounting for decision making and control (6 ${ }^{\text {th }}$ ed). New York: McGraw-Hill/Irwin 